\title{
USO DE TECNOLOGIAS NO ENSINO MÉDIO: PERCEPÇÃO E PRÁTICAS DE PROFESSORES DE EDUCAÇÃO FÍSICA
}

\author{
USO DE TECNOLOGÍAS EN LA ESCUELA SECUNDARIA: PERCEPCIÓN Y PRÁCTICAS DE LOS \\ PROFESORES DE EDUCACIÓN FÍSICA
}

https://orcid.org/0000-0002-2982-7074 Gelsimar José Machado https://orcid.org/0000-0002-9112-8119 José Edson Ferreira da Costa https://orcid.org/0000-0003-4257-0717 Claudia Maria Soares Rossi

${ }^{\text {A }}$ Universidade Federal do Espírito Santo (UFES), Vitoria, ES, Brasil

${ }^{\mathrm{B}}$ Instituto Federal do Ceará (IFCE), Fortaleza, CE, Brasil

${ }^{\mathrm{C}}$ Instituto Federal de Minas Gerais (IFMG), Arcos, MG, Brasil

Recebido em: 02 jun. 2020| Aceito em: 17 mar. 2021 Correspondência: Gelsimar Machado (geljm@hotmail.com)

\begin{abstract}
Resumo
Este artigo teve como objetivo investigar e compreender como têm se dado as práticas pedagógicas de docentes de Educação Física no ensino médio quanto ao uso das Tecnologias da Informação e Comunicação (TIC) no desenvolvimento de suas aulas. Estudo qualitativo de caráter exploratório e descritivo com docentes de escolas públicas de Juazeiro do Norte (CE) e Santa Maria de Jetibá (ES). Vê-se a relevância das TIC no processo educacional e como recursos pedagógicos para fomentar o processo de ensino-aprendizagem de conteúdos da Educação Física, envolvendo docentes e alunos em ações criativas e participativas, bem como, em desafios diante das mudanças na atuação do educador.
\end{abstract}

Palavras-chave: Tecnologias da Informação e Comunicação; Ensino Médio; Educação Física; Docência.

\section{Resumen}

Este artículo tuvo como objetivo investigar y comprender cómo las prácticas pedagógicas de los maestros de Educación Física en la escuela secundaria se han llevado a cabo con respecto al uso de las Tecnologías de Información y Comunicación (TIC) en el desarrollo de sus clases. Fue un estudio cualitativo de carácter exploratorio y descriptivo en los colegios públicos de Juazeiro do Norte (CE) y Santa Maria de Jetibá (ES). Se observó la importancia de las TIC en el proceso educativo y como recursos pedagógicos para mejorar el proceso de enseñanzaaprendizaje del contenido de Educación Física, involucrando a maestros y estudiantes en situaciones creativas y participativas, así como un desafío frente a los cambios en la práctica docente.

Palabras clave: Tecnologías de Información y Comunicación; Escuela Secundaria; Educación Física; Docencia.

\section{Introdução}

Tradicionalmente, a disciplina de Educação Física envolve como conteúdos básicos elementos da cultura corporal de movimento (jogos, brincadeiras, esportes, ginásticas, lutas e 
danças). No atual contexto, sobretudo nas aulas do ensino fundamental anos finais $\left(6^{\circ}\right.$ ao $9^{\circ}$ ano) e ensino médio ( $1^{\mathrm{a}}$ a $3^{\mathrm{a}}$ série), é necessário aliar as tradicionais aulas com o uso de recursos tecnológicos que tenham relação direta com a realidade dos estudantes.

Daolio (1996) menciona a importância de a Educação Física atuar na escola de forma que atenda a uma sistematização desse conhecimento ao longo de todo percurso escolar, nos mesmos modelos das outras disciplinas escolares. A história, por exemplo, deve organizar as informações populares trazidas pelos alunos, a fim de desenvolver e estimular novas práticas. Seguindo esse raciocínio, a Educação Física escolar deve iniciar um trabalho a partir do conhecimento corporal popular e das suas variadas formas de expressão cultural, esperando que o aluno adquira aprendizagem de forma organizada, crítica e autônoma a respeito da chamada cultura humana de movimento.

Para Carvalho Júnior (2015), o jogo virtual e as tecnologias da informação e comunicação (TIC) devem ser incorporados como ferramentas didáticas e pedagógicas. Esta utilização tem sido evidenciada em alguns estudos, tais como a utilização do jogo Dance Dance Revolution (DDR) (FINCO; FRAGA (2012), os tapetes de dança no currículo da Educação Física em escolas americanas (SCHIESEL, 2007) e a produção de blogs para o ensino de conteúdos (BIANCHI; PIRES, 2010). Os exergames também entram nessa lista e surgem como novas possibilidades para os videogames que necessitam de algum movimento físico para se jogar, sendo uma forma contemporânea de exercício físico (VAGHETTI; MUSTARO; BOTELHO, 2011; FINCO; ZARO, 2015).

Carvalho Júnior (2015) destaca que a utilização de jogos eletrônicos passa a ser relevante quando há mediação do professor e objetivos claros, pois a tecnologia isolada não assegura o sucesso do aprendizado. Para resultados significativos de sua utilização nas aulas de Educação Física, é preciso que a tecnologia seja acompanhada de um processo metodológico que tenha sentido e seja atrelado ao processo de ensino e aprendizagem.

Ao analisarem sobre a Educação Física no ensino médio, Betti e Zuliane (2002) observam que esta disciplina deve propiciar o atendimento desses novos interesses, e não reproduzir simplesmente o modelo tradicional de ensino pautado no quesito procedimental das atividades físicas e esportivas. Destacam que a Educação Física deve apresentar características próprias e inovadoras, que considerem a nova fase cognitiva e afetivo-social atingida pelos adolescentes.

A nova Base Nacional Comum Curricular (BNCC) destaca a necessidade de recriação da escola e reconhece que as rápidas transformações na sociedade envolvem diretamente a 
juventude, especialmente os avanços tecnológicos. Segundo o documento, este panorama impõe desafios à etapa do ensino médio que deve estar comprometida com a educação integral dos estudantes. A BNCC entende que a escola precisa se apropriar das linguagens das tecnologias digitais e sua utilização. Em tópico específico, a Base enfatiza o reconhecimento das tecnologias digitais e sua utilização para compreender e produzir conteúdo em todas as áreas de conhecimento.

Um dos grandes avanços quanto ao uso de tecnologias na BNCC que tem como ênfase os próprios estudantes é abordar Jogos Eletrônicos como objeto de conhecimento nas etapas do $6^{\circ}$ e $7^{\circ}$ ano do ensino fundamental II, como parte da unidade temática de Brincadeiras e Jogos da disciplina de Educação Física. De maneira direta, o documento reconhece a necessidade de abordagem deste conteúdo como parte intrínseca da juventude contemporânea. Enquanto habilidades a serem desenvolvidas a partir do Jogos Eletrônicos, a BNCC aponta como objetivos não apenas a vivência, mas sua problematização:

1) Experimentar e fruir, na escola e fora dela, jogos eletrônicos diversos, valorizando e respeitando os sentidos e significados atribuídos a eles por diferentes grupos sociais e etários. e 2) Identificar as transformações nas características dos jogos eletrônicos em função dos avanços das tecnologias e nas respectivas exigências corporais colocadas por esses diferentes tipos de jogos. (BRASIL, 2018, p. 233)

A inserção deste conteúdo na educação básica demonstra a relevância que estas tecnologias têm tido nas novas gerações.

Apesar de não indicar o uso de jogos eletrônicos dentre os conteúdos como no ensino fundamental II, no ensino médio, além da experimentação de novas práticas corporais (jogos e brincadeiras, esportes, danças, lutas, ginásticas e práticas de aventura), a BNCC propõe que a Educação Física desafie a reflexão dos estudantes sobre estas práticas, os limites do corpo, o estilo de vida ativo para a manutenção da saúde e as possibilidades de utilização de espaços públicos e privados.

A Educação Física, assim como as demais disciplinas, deve estar contextualizada com as tecnologias que fazem parte do cotidiano dos alunos. Neste processo, o professor tem papel fundamental ao buscar estratégias que possibilitem que o processo de ensino e aprendizagem ocorra de maneira que mantenha os alunos motivados, interessados e engajados. Pode-se mencionar, por exemplo, o uso de novas tecnologias a partir das Metodologias Ativas de Aprendizagem (CARVALHO JUNIOR, 2015).

Contudo, este estudo parte do seguinte questionamento: será que os professores de Educação Física estão aptos a trabalharem com as tecnologias em suas aulas de forma 
adequada? Assim, interessa-nos investigar como têm se dado as práticas pedagógicas de docentes de Educação Física atuantes no ensino médio quanto ao uso das tecnologias no desenvolvimento de suas aulas.

As novas tecnologias aliadas com a Educação Física escolar podem se tornar instrumentos transformadores, contribuindo para o desenvolvimento e formação dos estudantes (ROSENAU; SILVA, 2016).

A partir da problemática, teve-se como objetivo geral investigar e compreender como têm se dado as práticas pedagógicas de docentes de Educação Física atuantes no ensino médio quanto ao uso das tecnologias no desenvolvimento de suas aulas.

Para mediar o alcance do objetivo geral, foram estabelecidos os seguintes objetivos específicos: $1^{\circ}$ ) Compreender as características das práticas pedagógicas que os/as docentes de Educação Física estão efetivando nas escolas com auxílio da tecnologia; $2^{\circ}$ ) Verificar de que forma as TIC são utilizadas pelos docentes como ferramentas de aprendizagem nas aulas de Educação Física; $3^{\circ}$ ) Refletir sobre as práticas aliadas à tecnologia como possibilidades de aprendizagem.

\section{Percurso Metodológico}

Para a realização deste estudo, foi realizada uma pesquisa de caráter exploratório e descritivo pautada nos pressupostos da abordagem qualitativa (GIL, 2008; MALHOTRA, 2006). Este tipo de estudo está centrado na descrição detalhada, análise e interpretação das informações que são produzidas no processo de investigação em seus contextos específicos (NEGRINE, 2004; HERIVELTO; CALEFFE, 2006).

\section{Delimitação da área de pesquisa e participantes}

A pesquisa foi realizada em duas escolas públicas dos municípios de Juazeiro do Norte - CE e Santa Maria de Jetibá - ES, sendo as escolas de esfera estadual.

Foram investigados, por escola, dois professores de Educação Física que atuassem no ensino médio, totalizando quatro professores investigados. Para participação neste estudo foram estabelecidos alguns critérios:

1) Ter formação e lecionar a disciplina de Educação Física no ensino médio;

2) Atuar como docente da instituição há pelo menos um ano.

\section{Coleta de dados}


Inicialmente foram selecionadas as escolas para a realização da coleta de dados já conhecidas pelos autores do referido trabalho e, em seguida, através de contato via e-mail, foi solicitado aos diretores o consentimento, por meio da assinatura da Declaração de Anuência, para pesquisar sobre a realidade das práticas pedagógicas pelos docentes no estabelecimento de ensino.

Os sujeitos investigados foram contatados através do aplicativo whatsapp no mês de março/2020 e informados sobre os objetivos e procedimentos da pesquisa. Após a confirmação de sua participação de forma voluntária, foram enviados via e-mail o Termo de Consentimento Livre e Esclarecido (TCLE) e o questionário semiestruturado elaborado pelos autores do estudo a ser preenchido entre março e abril/2020.

Devido a atual situação enfrentada no Brasil e nos outros países acerca da Covid-19, ficou inviável o contato direto com os participantes da pesquisa devido à suspensão das aulas no Ceará através do Decreto $\mathrm{N}^{\mathrm{o}} 33.510$ de 16 de março de 2020 e posteriormente o Decreto $\mathrm{N}^{\mathrm{o}}$ 33.532 de 30 de março de 2020 e no Espírito Santo pelo Decreto No 4597-R de 16 de março de 2020 e Decreto No 4625-R, de 04 de abril de 2020.

Quadro 1 - Questionário utilizado com os docentes.

\begin{tabular}{|c|l|}
\hline & \multicolumn{1}{|c|}{ Perguntas } \\
\hline 1 & $\begin{array}{l}\text { Você acredita na inserção das tecnologias nas aulas de Educação Física escolar } \\
\text { para o ensino médio? Justifique. }\end{array}$ \\
\hline 2 & $\begin{array}{l}\text { Você considera as preferências dos estudantes ao elaborarem os Planos de } \\
\text { Ensino? }\end{array}$ \\
\hline 3 & $\begin{array}{l}\text { Você utiliza tecnologias para auxiliar no processo de ensino e aprendizagem? E } \\
\text { quais tecnologias costuma usar? }\end{array}$ \\
\hline 4 & $\begin{array}{l}\text { Já fez uso das Tecnologias de Informação e Comunicação na execução de algum } \\
\text { projeto educativo para o ensino médio na área da Educação Física? }\end{array}$ \\
\hline 5 & $\begin{array}{l}\text { Quais os resultados obtidos com o uso das Tecnologias de Informação e } \\
\text { Comunicação na execução desses projetos? }\end{array}$ \\
\hline 6 & Conhece algum termo ligado às TIC que designem as novas gerações? \\
\hline 7 & O modo de aprender dos estudantes do ensino médio mudou nos últimos anos? \\
\hline
\end{tabular}

Fonte: Elaborado pelos autores (2020).

Para Pereira (2009) o questionário on-line, além de prático, é um recurso de fácil acesso, tornando-se mais objetivo e dinâmico que os questionários tradicionais impressos. Já Costa (2012) reforça que o questionário on-line não desconfigura a estrutura e nem limita o que se quer apresentar aos sujeitos pesquisados. 


\section{Análise dos dados}

Para analisar as informações obtidas a partir do questionário, foi utilizada a análise de conteúdo (BARDIN, 2009). Destaca-se que o conteúdo do questionário foi analisado, codificado e organizado pelas ideias centrais e expressões-chave, para que assim pudéssemos interpretar os dados colhidos e dispô-los em categorias. Contudo, serão apresentadas apenas as respostas que reflitam uma grande importância para o estudo, sem que tenham perda da compreensão do fenômeno em questão.

Os questionários foram organizados em um quadro contendo todas as respostas de todos os docentes, que foram identificados pela letra P (P1, P2, P3 e P4) e então analisadas e classificadas em categorias.

\section{Resultados e Discussões}

Os docentes que participaram deste estudo possuem uma diferença de experiência de 10 anos, isto porque, a mais jovem está há dois anos no exercício da profissão, enquanto o mais experiente está há doze anos.

A partir das respostas dos questionários e análises, emergiram três categorias:

Categoria 1: Conhecimento sobre as Tecnologias de Informação e Comunicação - TIC;

Categoria 2: Uso das TIC no planejamento e nas aulas de Educação Física;

Categoria 3: Percepções de aprendizagens com TIC e nível de conhecimento dos docentes.

\section{Conhecimento sobre as Tecnologias de Informação e Comunicação - TIC}

Nesta categoria, foi realizada a análise referente às perguntas que abordavam sobre a implantação/inclusão das tecnologias nas aulas de Educação Física, e se os docentes conhecem termos ligados às TIC que estejam associados às novas gerações.

Sobre a inserção das TIC nas aulas de Educação Física, todos os entrevistados foram afirmativos nas respostas, evidenciando a importância desta ferramenta para o desenvolvimento do processo de ensino e aprendizagem. Entretanto, três professores apontaram ressalvas:

P1: Acredito, a tecnologia pode auxiliar em diversos fatores no processo de aprendizado embora ainda seja desafiador a forma de utilização.

P2: Sim! [...] porém, devemos levar em consideração que existem muitos problemas no que diz respeito ao uso dessas tecnologias. Torna-se desafiador, principalmente para os professores, sair do "método tradicional de ensino" para essa nova ferramenta. P4: Sim, acredito. [...] Porém é necessária uma avaliação, ou melhor, uma filtragem dos meios tecnológicos para que não se perca o principal caminho de ensino, nesse caso, o movimento. 
Nota-se, nos discursos dos docentes, a importância da tecnologia aliada à educação, porém é preciso romper a ideia de que a tecnologia está restrita apenas aos meios eletrônicos e/ou digitais (LOPES; MONTEIRO, 2014). Para Nogaro e Cerutti (2016) não existe um percurso pronto, uma concepção fiel a seguir de como trabalhar o ensino/aprendizagem na cibercultura, contudo é necessário repensar propostas para serem utilizadas e adaptadas para a busca do conhecimento nesse novo contexto.

Para os docentes P1 e P2 o uso das TIC é “desafiador”, e essa é uma realidade de muitos professores. Prioste (2013) reforça que muitos educadores se sentem intimidados por não dominarem as tecnologias. Convém ressaltar que a superação quanto a essas práticas não irá acontecer em um curto intervalo de tempo, é um processo lento e contínuo, acima de tudo, iniciativa de querer mudar essa realidade, fazer diferente. A formação continuada enfatizando o uso das TIC pauta-se como processo imprescindível para alavancar o nível de educação básica.

Quanto aos termos ligados às TIC presentes nas novas gerações, os entrevistados reconhecem que o celular e os aplicativos (apps) são partes integrantes entre os alunos.

\footnotetext{
P1: APP (aplicativo). Eles facilitam e muito as nossas vidas, inclusive aprendi com os meus alunos a utiliza-los em algumas aulas.

P4: Os aplicativos são os mais usados, citados.
}

Observa-se no relato do P1 que o conhecimento desta TIC foi promovido pelos próprios alunos. Observa que o celular passou a ser frequentemente utilizado nas aulas como ferramenta pedagógica, mas também para fins não educativos. Ainda que se entenda que o uso dos dispositivos móveis faz parte da vida dos alunos, chegando a ser uma extensão do próprio corpo e como ferramenta indispensável no dia a dia (AMANTE, 2014). É indiscutível que os limites se façam presentes no ambiente escolar através do Projeto Político Pedagógico, projetos de intervenção e trabalhos de conscientização que possam ser a solução para a questão. Como consta no relato a seguir, é preciso uma nova dinâmica nas aulas a partir dos aparelhos tecnológicos, especialmente o celular.

P3: [...] o uso desse aparelho causou impacto na vida estudantil e social de muitos jovens, pois na maioria das vezes o celular era usado para fins não educativos, o que acabava havendo divergências nos estudos.

Atrelar o processo educacional com o uso das TIC está presente na realidade dos professores pesquisados. Por isso, o desafio principal parece ser em utilizar estas ferramentas, sobretudo os smartphones, como metodologia no desenvolvimento dos conteúdos, já que é impossível se desvincular deste aporte tecnológico que está cada vez mais presente na vida dos estudantes e na sociedade em geral. 


\section{Uso das TIC no planejamento e nas aulas de Educação Física}

Esta categoria contemplou a análise referente às perguntas que abordavam a utilização das tecnologias no planejamento do docente e a aplicabilidade nas tarefas em aula ou desenvolvimento de projetos com os alunos, questionando os professores sobre quais recursos são utilizados geralmente em suas aulas e forma de condução das aulas com a utilização das TIC.

Os entrevistados foram unânimes em responder de forma positiva quando questionados sobre considerar a preferência dos estudantes na organização do plano de ensino. Em especial sobre as TIC temos:

P3: [...] é importante o professor levar isso em consideração. Porque o que mais está atraindo os alunos é a tecnologia. Então, os conteúdos devem ser pensados de forma que atraia e desperte o interesse no aprender dos alunos.

Betti e Zuliane (2002) observam uma desmotivação em relação à Educação Física na etapa do ensino médio, atribuindo pouco crédito à atividade física que despertava muito mais interesse no início da adolescência. Os autores sugerem não propor nesta etapa apenas as práticas corporais da Educação Física vistas no ensino fundamental, mas sim temas que sejam interesse dos alunos e que fazem parte de sua etapa de vida, que considerem a nova fase cognitiva, afetiva e social.

A forma de ensino tradicional pautada na transmissão de conhecimento por parte do professor - denominado por Paulo Freire de Conhecimento Bancário (FREIRE, 1996) - tem sido uma prática condenada nas últimas décadas. Contudo, este ensino tradicional, refutado pela vertente progressista, nem sempre chega à ponta, no cotidiano de ensino. Por mais que o currículo propicie esta forma de atuação, alguns fatores podem ser considerados que impedem sua efetivação na prática, entre eles a formação deficiente, seja por meio da instituição de ensino ou do interesse do próprio docente.

Em oposição ao modo tradicional centrado no professor, o modelo progressista busca enfatizar, também, o conhecimento do aluno e seu interesse no processo de aprendizagem. Em certa medida, que este modelo está presente nas respostas dos docentes pesquisados, pois, despertar o interesse dos discentes para o aprendizado, que vai além do ensino de práticas corporais, contribui para a eficiência do processo de ensino, já que a tecnologia tem feito parte do mundo contemporâneo. Gerar o protagonismo estudantil e dar ouvido às suas demandas estão entre as propostas da BNCC para a etapa do ensino médio (BRASIL, 2018). 
Os professores não desenvolveram grandes projetos com o uso das TIC, mas afirmam utilizar essas ferramentas na abordagem dos conteúdos e na apresentação de trabalhos pelos alunos.

P3: Nas aulas e apresentação dos conteúdos, seja por minha parte ou dos alunos através de trabalhos e seminários, a gente sempre está procurando fazer uso destas tecnologias para que a gente possa apresentar o trabalho de forma dinâmica, os conteúdos também de forma atrativa.

P4: Não executei nenhum projeto específico ou grande, não. Mas, dentro das aulas de Educação Física eu trabalhei os conteúdos, como Corrida de Orientação que utilizei a bússola; alguns outros conteúdos.

A apropriação de recursos tecnológicos por parte dos professores vai ao encontro das demandas educacionais presentes, sobretudo, em cidades onde o acesso à rede de telefonia móvel e internet é parte da realidade dos estudantes. Trata-se de uma nova dinâmica (talvez nem tão nova assim!) do trabalho docente na área de Educação Física.

Tradicionalmente pautada ao longo dos anos sob os aspectos técnicos de diferentes práticas corporais, a Educação Física segue passando por reformulações e constantes desafios. Dentre estes, destaca-se o uso das novas tecnologias na abordagem dos conteúdos, em especial no ensino médio. A metodologia tradicional pautada sobre a rigidez do aspecto procedimental que enfatiza os gestos técnicos não tem despertado interesse no público escolar desta etapa.

Esse fato tem exigido do docente outras formas de trabalho nos últimos anos, como o uso de métodos a partir das TIC, como é possível verificar nos relatos:

P3: Os resultados obtidos não são $100 \%$, mas uma grande maioria tem um resultado positivo na aprendizagem, com um resultado de aprendizagem mais significativa quando se faz uso destas tecnologias.

P4: Pensando para dentro da aula, o uso do celular neste caso, foi valido. Trabalhei os objetivos, consegui ensinar e eles conseguiram interpretar isso. Então, foi bastante válido.

Em relação ao uso das TIC pelos alunos, é preciso ressaltar que nem sempre será um processo dinâmico e automaticamente desenvolvido. Como exposto por um dos entrevistados, houve certa dificuldade por parte de alguns discentes na concretização das tarefas relacionadas ao aplicativo solicitado. Esse ponto merece atenção, pois o uso dos smartphones nas aulas, por exemplo, nem sempre se repercutirá em efeitos positivos, haja vista o interesse dos alunos por diferentes sítios presentes na vasta rede de internet, especialmente no que concerne aos sites e aplicativos que envolvem as redes sociais.

P4: [...] mas ainda assim há uma falta de vontade e interesse; tive que fazer grupos. Então, por mais que seja fácil este contato com a tecnologia, ainda há um despreparado dos alunos. 
Apesar de algumas divergências presentes com os usos das TIC pelos discentes, Baracho, Gripp e Lima (2012) entendem que a virtualidade proporcionada pelos meios tecnológicos, principalmente jogos de videogame de movimentação corporal. Os exergames se configuram como um caminho propício para restaurar o interesse dos alunos pelas práticas corporais nas aulas de Educação Física e fora dela. Tal proposta é coerente com os pressupostos adotados pela BNCC (BRASIL, 2018) para a etapa do ensino médio, ressaltando a ênfase no reconhecimento das potencialidades das diferentes tecnologias digitais para a realização de atividades que atravessam distintas áreas do mundo contemporâneo.

\section{Percepções de aprendizagens com TIC e nível de conhecimento dos docentes}

Esta categoria teve o intuito de entender como os professores veem a aprendizagem dos alunos nas situações em que fazem uso, em sala de aula, de recursos tecnológicos como ferramentas didáticas e quais tecnologias costumam usar. E, ainda, como percebem o nível de conhecimento dos alunos diante do atual contexto tecnológico.

Os professores usam diferentes modos tecnológicos para abordarem os conteúdos de suas aulas.

\footnotetext{
P1: [...] utilizo as tecnologias mais nas aulas teóricas, com computadores para fazer pesquisas sobre temas abordados nas aulas, notebook e Datashow para apresentações de slides ou vídeos e já utilizei celulares com jogos principalmente em jogos de tabuleiros.

P2: Mais comuns, notebook e celular.

P3: vídeos, blogs, produção e análise de vídeos, muito conteúdo do youtube, jornais on-line e impresso, internet para pesquisa em sites oficiais. 4

P4: A internet, dentro (com os chromebooks) e fora da escola. Já usei o celular para funções básicas de internet, calculadora e bússola.
}

As diferentes ferramentas utilizadas pelos professores pesquisados revelam a mudança ocorrendo no ensino da disciplina de Educação Física no ensino médio. Tais métodos demonstram, em certa medida, o esforço que o sistema educacional tem efetuado para acompanhar os processos de transformação que o mundo rapidamente tem sofrido. E, dentre estes sistemas de mudança, a escola tem apresentado defasagem.

Especificamente sobre a disciplina de Educação Física, entende-se que o seu papel, no ensino médio, distinto das outras etapas da educação básica, é preparar os estudantes para acesso ao mundo de trabalho, não cabendo a ênfase do ensino que evocam a aprendizagem de gestos motores de alto nível.

É preciso acentuar que a Base Nacional Comum Curricular (BNCC, 2018), para o ensino médio, quando se refere à Educação Física, acaba beirando a invisibilidade de toda a importância que poderia ser dada. Mas, cabe frisar que o documento contempla o 
desenvolvimento de competências e habilidades relacionadas ao uso crítico e responsável das tecnologias digitais presentes em todas as áreas do conhecimento e com objetivos de aprendizagens diferenciadas como destaca a Competência Geral 5:

Compreender, utilizar e criar tecnologias digitais de informação e comunicação de forma crítica, significativa, reflexiva e ética nas diversas práticas sociais (incluindo as escolares) para se comunicar, acessar e disseminar informações, produzir conhecimentos, resolver problemas e exercer protagonismo e autoria na vida pessoal e coletiva (BRASIL, 2018, p. 8).

Assim, é preciso lembrar que incorporar as tecnologias digitais na educação vai além de utilizar como suporte que promova aprendizagem, mas sim ser um meio de utilizá-las no processo educacional para que se construam conhecimentos com e sobre as TIC.

Parece-nos que os professores entrevistados entendem ser outro o papel da Educação Física no ensino médio e a função da tecnologia como aliada para a aprendizagem dos alunos. Questionados sobre as mudanças no modo de aprender dos discentes, temos:

\footnotetext{
P1: [...] a forma como os alunos aprendem vem mudando, pois, a tecnologia auxiliou com diversas ferramentas. Facilitando as pesquisas, acesso a revistas, livros e jornais, a notícias agora está na palma de suas mãos.

P2: Hoje, sabemos que a tecnologia predomina e o acesso a essas ferramentas para o estudo está cada vez melhor, tornando-os essenciais no processo de aprendizagem do aluno.

P3: Está diferente sim, haja a vista que as formas de ensinar também evoluíram, e evoluíram muito e para melhor. Vem para contribuir de forma efetiva para a aprendizagem dos alunos. Se o modo de aprender deles [os alunos] é diferente, então a gente precisa estar atento a isso para poder agrega-los Às nossas formas de ensinar, levando sempre em consideração as tecnologias, porque é isso que atrai eles. E isso tem contribuído muito para a aprendizagem para grande maioria dos alunos.

P4: Hoje percebo que os estudantes estão mais "visuais". A ânsia pela prática dos conteúdos de educação física tem diminuído em relação a quando eu era estudante, por exemplo.
}

Como percebido pelos quatro pesquisados, há mudanças proporcionadas pelas TIC que influenciam na aprendizagem dos estudantes, algo que será mais explícito com o decorrer dos anos. Concordamos com Baracho, Gripp e Lima (2012) quando afirmam que a cultura digital é inevitável, cabendo aos professores estarem sucessíveis ao cenário inovador para absorver e potencializar o uso destas diferentes tecnologias.

\section{Considerações Finais}

Diante de tantos avanços evidenciados ao longo das últimas décadas, faz-se necessário que a sociedade contemporânea esteja conectada aos meios digitais, processo que vem se desenvolvendo espontaneamente na medida em que os avanços tecnológicos estejam disponíveis a partir de diferentes softwares e hardwares que alcançam todas as classes sociais. Fazer o uso das TIC é estar em comunicação e desenvolvimento constante. 
Assim, é possível notar, por meio das entrevistas realizadas, que, apesar das dificuldades encontradas no ambiente escolar para o uso das ferramentas digitais, é preciso conciliar o uso das TIC no planejamento e no processo de ensino e aprendizagem, rever os métodos, repensar e avaliar todo processo de forma mais abrangente e com flexibilidade para atender as expectativas de uma geração que nasceu no mundo da tecnologia.

Observou-se que, ainda pontuais, ações são colocadas em práticas, na tentativa de estimular a aprendizagem dos alunos se adequando às novas demandas educacionais, mesmo apresentando algumas dificuldades devido à rápida transformação tecnológica. Apesar disso, os docentes desta pesquisa enxergam as TIC como ferramentas com mais espaço na educação e nas aulas de Educação Física e como métodos para o desenvolvimento das aulas no ensino médio. Instigar a participação dos alunos nas aulas que contemplam essa etapa da educação básica a partir de diferentes metodologias, e o uso das TIC é uma delas, pode contribuir para o maior interesse desse público na disciplina de Educação Física e em outras, até mesmo na própria escola, já que a elevada taxa de evasão, nesse período, é evidente.

Dada a relevância do assunto abordado, é preciso investigar sobre a aplicabilidade do uso das TIC nas aulas de Educação Física. Nas falas dos docentes, é possível perceber relatos positivos, mas limitados em muitos momentos, e isso consequentemente acontece pela falta de formação continuada e o não uso das tecnologias a favor da realidade em questão. Este cenário pode evidenciar, entre outros fatores, o imenso eco existente entre a rapidez com que se propagam os incrementos tecnológicos na sociedade de modo geral e sua utilização como métodos educacionais em escolas públicas.

Ainda que de forma gradual, é necessária uma maior interação entre a escola e as tecnologias, o que se traduz em muitos desafios ao atuar na docência. Apesar dos aspectos relacionados sobre o papel dos professores com diferentes possibilidades de utilizar distintas tecnologias para mediar a produção do conhecimento dos estudos, a responsabilidade em agregar os avanços tecnológicos ao meio educacional não é apenas deste profissional. Permitir que os avanços tecnológicos, por mais singelos que pareçam ser, sejam uma realidade presente na diversidade de instituições presentes neste imenso país dependem de ações que ultrapassam a capacidade docente, mas que dependem também de diferentes campos, como a economia e as políticas públicas. 


\section{Referências}

AMANTE, L. Facebook e novas sociabilidades: contributos da investigação. In: PORTO, C.; SANTOS, E. (Orgs.) Facebook e educação: publicar, curtir, compartilhar. Campina Grande: EDUEPB, 2014, p. 27-46.

BARACHO, A. F. de O.; GRIPP, F. J.; LIMA, M. R. de. Os exergames e a educação física escolar na cultura digital. Rev. Bras. Ciênc. Esporte, Florianópolis, v. 34, n. 1, p. 111-126, jan./mar. 2012.

BARDIN, L. Análise de Conteúdo. Lisboa, Portugal: Edições 70, LDA, 2009.

BETTI, M.; ZULIANI, L. R. Educação Física Escolar: uma proposta de diretrizes pedagógicas. Revista Mackenzie de Educação Física e Esporte - v. 1, n. 1, p. 73-81, 2002.

BIANCHI, P.; PIRES, G. de L. Possibilidades para o ensino-aprendizagem com TICs na educação física escolar: uma experiência com blogs. Cadernos de Formação RBCE, p.45-55, mar. 2010.

BRASIL. Base Nacional Comum Curricular/Ministério da Educação. Secretaria de Educação Básica. Diretoria de Currículos e Educação Integral. Brasília: MEC, 2018.

BRASIL. Decreto No 33.510. Diário Oficial do Estado do Ceará, Poder Executivo, Fortaleza, CE, 16 de março de 2020. Disponível em: < https://www.cge.ce.gov.br/decretos-estaduais>. Acesso em: 10 abr. 2020.

BRASIL. Decreto No 33.532. Diário Oficial do Estado do Ceará, Poder Executivo, Fortaleza, CE, 30 de março de 2020. Disponível em: <https://www.cge.ce.gov.br/decretos-estaduais>. Acesso em: 10 abr. 2020.

BRASIL. Decreto No 4.597-R. Diário Oficial dos Poderes do Estado, Poder Executivo, Vitória, ES, 16 de março de 2020. Disponível em: < https://sedu.es.gov.br/escolar/legislacoes>. Acesso em: 10 abr. 2020.

BRASIL. Decreto No 4.625-R. Diário Oficial dos Poderes do Estado, Poder Executivo, Vitória, ES, 04 de abril de 2020. Disponível em: < https://sedu.es.gov.br/escolar/legislacoes > Acesso em: 10 abr. 2020.

CARVALHO JUNIOR, A. F. P. As tecnologias nas aulas de educação física escolar. Anais. XIX Congresso Brasileiro de Ciências do Esporte. Vitória, ES, 2015.

COSTA, T. V. Atuação profissional de enfermeiros egressos do currículo integrado de uma universidade pública do norte do Paraná. 2012.159 f. Dissertação (Mestrado em Enfermagem) - Universidade Estadual de Londrina, Londrina, 2012.

DAOLIO, J. Educação física escolar: em busca da pluralidade. Revista Paulista de Educação Física. São Paulo, n. 2, p. 40-42, 1996.

FINCO, M. D.; FRAGA, A. B. Rompendo fronteiras na Educação Física através dos videogames com interação corporal. Motriz, Rio Claro, v.18, n.3, p.533-541, 2012.

FINCO, M; ZARO, M. Laboratório de exergames na educação física: conexões por meio de videogames ativos. Tese (Doutorado em informática na Educação), Centro de Estudos Interdisciplinares em Novas Tecnologias na Educação. UFRGS. Porto Alegre, pag. 164, 2015. FREIRE, P. Pedagogia da autonomia: saberes necessários à prática educativa. São Paulo: Paz e Terra, 1996.

GIL, A. C. Métodos e Técnicas de Pesquisa Social. 6. ed. São Paulo: Atlas, 2008. 
HERIVELTO, M.; CALEFFE, L. G. Metodologia da Pesquisa para o professor pesquisador. Lamparina, 2006.

LOPES, A. H. R. G. P; MONTEIRO, M. I; MILL, D. R. S. Tecnologias Digitais no contexto escolar: Um estudo bibliométrico sobre seus usos, suas potencialidades e fragilidades. Revista Eletrônica de Educação, v. 8, n. 2, p. 30-43, 2014.

MALHOTRA, N. K. Pesquisa de marketing: uma orientação aplicada. 4. ed. Porto Alegre: Bookman, 2006.

NEGRINE, A. Instrumentos de coleta de informações na pesquisa qualitativa. In: TRIVINOS, A.N.S. et al (Orgs.). A pesquisa qualitativa na Educação Física. 2. ed. Porto Alegre: Editora da UFRGS/Sulina, 2004, p. 61-93.

NOGARO, A; CERUTTI, E. As TICs nos labirintos da prática educativa. Curitiba: CRV, 2016.

PEREIRA, M. M. B. A. Google Docs: uma experiência no Ensino Profissional. 2009. 103 p. Dissertação (Mestrado em Multimídia) - Faculdade de Engenharia da Universidade do Porto, 2009.

PRIOSTE, C. D. O adolescente e a Internet: laços e embaraços no mundo virtual. 2013. 361 p. Tese (Doutorado no Programa de Pós-Graduação em Educação) - Faculdade de Educação da Universidade de São Paulo, 2013.

ROSENAU, N. R.; SILVA, M. S. Contribuições das tecnologias móveis na educação física escolar. In: Os desafios da escola pública paranaense na perspectiva do professor PDE. Volume 1. PR. 2016.

SCHIESEL, S. P. E. Classes turn to video game that works legs. The New York Times, 30 de Abril, 2007. Disponível em:

$<$ https://www.nytimes.com/2007/04/30/health/30exer.html>. Acesso em: 30 abr. 2020.

VAGHETTI, C. A. O.; MUSTARO, P. N.; BOTELHO, S. S. C. Exergames no ciberespaço: uma possibilidade para educação física. In: Proceedings of X SIMPÓSIO BRASILEIRO DE JOGOS E ENTRETENIMENTO DIGITAL, Salvador, 2011. 